\title{
Structural and functional social support in elderly objective and subjective health ratings
}

\author{
Sergio Iglesias ${ }^{1}$ and Ana V. Arias ${ }^{2}$ \\ ${ }^{1}$ University of Jaen (Spain); ${ }^{2}$ National Distance \\ Education University (UNED), Madrid (Spain)
}

This paper aims to investigate the causes that explain the discrepancies between the effects of social relationships on health and wellness of the elderly people. Several disciplines of health sciences have developed different theories to explain the evidence that confirm the positive effects of social relations. Furthermore, there is acumuative evidence confirming most of the predictions derived from its principles. However, the empirical evidence has not always confirmed these beneficial relationships and sometimes these evidences contradict some of the theoretical predictions. Even, it is not difficult to find reversed effects. In this paper we follow some of the approaches developed from Social Psychology which analyze the different effects of social relationships on the health of older people. Two types of aspects of social relations have served to this purpose. First, the structural aspects (i.e., frequency of intercourse). Second, qualitative-functional aspects of great tradition in estudies of quality of life and wellbeing of older people (i.e. social support). Following the Convoy Model, we measured perceived social support and frecuency of relationships in 168 spaniards, men and women (aged 62 years old and more). We analyze these discrepancies in the light of the underlying mechanisms.

Keywords: Social support given, social support received, perceived health, objective health, old age.

Aspectos estructurales y funcionales del apoyo social y su impacto en la salud objetiva y percibida de los mayores de gran edad. Nuestro objetivo es aproximarnos a las discrepancias que existen entre los efectos de las relaciones sociales sobre la salud física y la salud percibida de las personas de mayor edad. Desde diferentes disciplinas dan cuenta de la evidencia empírica que avala los efectos beneficiosos de las relaciones sociales en la salud. No obstante, no siempre la evidencia empírica ha confirmado estos beneficios, y en ocasiones, contradice algunas de las predicciones teóricas. Siguiendo algunos de los enfoques desarrollados desde la Psicología Social, en este trabajo analizamos los efectos discrepantes de las relaciones sociales sobre la salud de personas de mayor edad. Dos tipos de aspectos de las relaciones sociales han servido a este objetivo. Por un lado, los aspectos estructurales (i.e., la frecuencia de relaciones) y por otro, ciertos aspectos cualitativo-funcionales de gran tradición en los estudios de calidad de vida y bienestar de las personas de mayor edad (i.e. el apoyo social). Siguiendo el modelo convoy de relaciones sociales, medimos la frecuencia de relaciones sociales y el apoyo social en una muestra de 168 españoles, hombres y mujeres, mayores de 62 años. Los resultados obtenidos confirman las discrepancias entre los efectos de las relaciones sociales. Analizamos estas discrepancias a la luz de los mecanismos motivacionales subyacentes.

Palabras clave: Apoyo social dado, apoyo social recibido, salud percibida, salud objetiva, adulto de gran edad.

Correspondence: Sergio Iglesias-Parro. University of Jaen. Las Lagunillas, s/n.

E-mail: siglesia@ujaen.es 
The social relations are a requirement for psychosocial growth and for social welfare. That is a principle that underlies many programs promoting community health and welfare of citizens (Aday et al., 1996; Chamberlain, Fetterman, \& Maher, 1994; Sanchez, Saez, \& Pinnazo, 2010). This statement is still receiving growing empirical support from different perspectives and scientific traditions (Psychology, Geriatrics, Nursing and remains of health sciences).

The empirical evidence bearing on this direction is abundant and leads to the conclusion that people with strong social relationships enjoys greater emotional wellbeing in their daily lives. There were also several beneficial effects on physical health (House, Landis, \& Umberson, 1988).

Following some of the approaches developed from Social Psychology, in the present work we analyze the effects of social support on health. Two types of properties of social relations have served to this purpose: the qualitative properties of the perceived welfare of older people (i.e., social support) and the structural properties (i.e., frequency of relationships or the number and type of social partners in a network).

\section{Social support}

There is ample research on social support and its putative impact on physical and mental health. However, obtained results of these investigations are so far inconclusive at most (Haber et al., 2007; Nurullah, 2012). Some research indicates that in general, perceived social support is associated with improved physical and mental health (Kafetsios \& Sideridis, 2006; Lakey \& Orehek, 2011; Uchino, Cacioppo, \& Kiecolt-Glaser, 1996), and that perceived support is more essential than received support in predicting adjustment to life stress (Wethington \& Kessler, 1986). In a similar vein, the absence of social resources constitutes a substantial health risk (Cacioppo, Hawkley, \& Thisted, 2010) and there is evidence that people who perceive that support is available to them have better health (House, Landis, \& Umberson, 1988). However, other studies have reported that supportive behaviors either have no positive effect on well-being (Barrera, 1986) or may even be detrimental to the recipient (Bolger \& Amarel, 2007; Martire et al., 2002) or to the provider (Schulz \& Sherwood, 2008).

Research attempting to explain this discrepancy have suggested that support efforts can be miscarried (Lehman \& Hemphill, 1990; Martire et al., 2002), or can create feelings of indebtedness or guilt to the support receiver (Bolger \& Amarel, 2007; Gleason et al., 2003). Although the evidence for the protective effects of social support on health outcomes is growing, the important question of the relevant underlying mechanisms remains unclear. In addition, it has proved difficult to determine exactly which aspects of social support have been responsible for the beneficial effects on mortality (Lyyra \& Heikkinen, 2006). 
In present work we are to focus on the different dimensions and measures of social support and their putative role to explain the discrepant effects of social support on health. From this point of view, some authors distinguish between structural and functional propierties of social relationships (Avlund et al., 2004). The former kind of propierties focuses on the individuals with whom one has an interpersonal relationship and the linkage between these individuals. They are more objetive measures (i.e. frecuency of relations, kind of ties between the members of networks, and others aspects like these) whereas the latter focuses more on the specific needs or motivations that relationship serve (i.e. sense of community, sense of belonging, connectiveness, sense of generativity and trascedence, and others).

\section{Self-rated health}

Self-rated health refers to a single-item measure in which individuals rate the current status of their own health on a Likert scale. It is popular for its simplicity and has been widely studied (Benjamins et al., 2004; Idler \& Angel, 1990) showing that is a good predictor of health (Kaplan, Barell, \& Lusky, 1988; Wu et al., 2013) but due to the fact that demographic and socioeconomic factors can influence how an individual evaluates his health, research has shown conflicting results.

Age, gender, education, and income, among other factors, have all been found to be significantly associated with the form of health is perceived. Thus, a number of research have reported that old people perceive their health in positive terms (Idler, 1993) and tend to over-estimate their health compared with objective health measurements. Other data support the view that elderly people are more pessimistic in their perceptions of their own health than younger people (Crossley \& Kennedy, 2002).

According to $\mathrm{Wu}$ et al., (2013) these moderating factors may confound the relationship between self-rated health and objective health measures because they influence both the independent and dependent variables. Thus, for instance, individuals with higher socioeconomic status score higher in self-rated health but also are characterized by lower levels of mortality than individuals with lower socioeconomic status (Franks, Gold, \& Fiscella, 2003).

The purpose of the present study is to examine whether the structural and functional dimensions of social support have different impact on health when measured objectively as well as on perceived health. In pursuing these goals, structural social support was measured following the Convoy Model of Social Relations (Antonucci, 1986) and perceived support was measured using the 2-Way Social Support Scale (Shakespeare-Finch \& Obst, 2011). We compared the impact of these support measures on perceived health as well as an objective indicator of health. 


\section{METHOD}

\section{Participants}

The questionnaire was administered to 168 participants ( 85 women). Age ranged between 62 and 92 years $(M=72.8, S D=7.1)$. The $51.2 \%$ of the sample were married, the $36.9 \%$ were widowed, whereas the $7.7 \%$ were single and the $4.2 \%$ were divorced. Only $19 \%$ have no children and $81 \%$ do have children (the $52.9 \%$ had between 1 and 2 children, the $17.9 \%$ had 3 children and $10.2 \%$ had 4 or more children). The $96.4 \%$ of the participants were living in private homes whereas the $2.4 \%$ of the sample were living in a residence.

\section{Instruments}

Data were registered through a questionnaire which was part of a broader study. Initially, participants were informed that the study aimed to learn some aspects of their personal relationships. The anonymity of their participation as well as the information they provided was guaranteed. The questionnaire was individually applied by a member of the research team, who according to the needs of each participant could read or not the items. Although the questionnaire included other measures, in this section we are to highlight the relevant variables for this study.

On the first page of the questionnaire, was drawn a diagram consisting of three concentric circles, each described according to the structure of the Convoy Model of Social Relations (Antonucci, 1986). The term convoy is used to mean a group of people moving together through life with mutual purpose. Each circle of the convoy represents a different degree of personal relationships. Participants were asked to list the names and type of links with people included in the inner circle of the model (people so close that it would be impossible to imagine life without them. Those who share our lives most intimately and for the longest times), in the circle 2 (people who are intimately a part of our life, but not much as the inner circle) and the circle 3 (persons who play a significant part in our lives, but not on a day-to-day basis).

The 2-Way SSS (2-Way Social Support Scale) (Shakespeare-Finch \& Obst, 2011), measures four dimensions of social support, namely, Emotional Support Received (ESR, items 1 to 7), Emotional Support Given (ESG, items 8 to 12), Instrumental Support Received (ISR, items 13 to 16), and Instrumental Support Given (ISG, items 17 to 21). The original scale was composed of 21-items scored on a 6-point Likert scale ranging from 0 (not at all) to 5 (always). Total scores can range from 0 to 100 with lower scores denoting less social support. In present study we used a modified version of the scale in which Yes-No answers were asked. Punctuations were normalized in order to facilitate comparison with previous research. Thus, in our scale total scores on each dimension can range from 0 to 100 with lower scores denoting less social support. 
Reliability of each dimension in the original scale was high, with alphas ranging from .76 to .92 (Shakespeare-Finch \& Obst, 2011). In our sample we obtained comparable alpha coefficients: ESR KR20=.77, ESG KR20=.74, ISR KR20=.75, and ISG $\mathrm{KR} 20=.74$.

On the last page of the questionnaire participants were asked for a variety of demographic data including sex, age, marital status, occupation, and educational level. They were also asked for the number of children, the number of people living at home and the place of residence (private home vs residence). Respondents were also asked if they had the responsibility of taking care of dependent family members on a four-point scale (0-never 1-sometimes, 2-with frequency, 3-daily). Related to health, participants were asked for the number of drugs they were taking daily. This was considered an objective health indicator. Moreover, participants have to do an assessment of their health status compared with other persons of the same age on a four-point scale (1excellent, 2-fairly good, 3-fairly bad, 4- very bad). This questions was considered a perceived health indicator.

\section{Procedure}

Data were collected with information provided by people aged over 64 years in the Community of Madrid. First an initial contact with each individual was held in which the purpose of the survey was explained and their voluntary participation was requested. Next and in order to facilitate data collection participants were offered the opportunity to complete the questionnaire with an evaluator or fill it privately.

\section{Data analysis}

To describe the general health level of participants, two indicators were obtained (objective and perceived). The objective (Number of pills I take every day) health indicator showed a median of 2 and a range from 0 to 8 pills per day.

In order to better understand this disparity, we constructed two stepwise regression models. Criterion variables were the two health measures (objective and perceived health). The predictors were the four dimensions we obtained fron social support scale.

\section{RESULTS}

\section{Objective and perceived health indicators}

The perceived (Regarding others, I feel that that my health is) health indicator showed a median of 2 from a range from 1 (Excellent) to 4 (Very Bad). For the purpose to know how our different health measures were related, Spearman rank order correlation coefficient was obtained between the objective and the perceived health 
indicators. Results showed that $\left(r s_{(168)}=.56 ; p<.01\right)$ even though significant, the relationship between the measures was not as high as expected $\left(\mathrm{R}_{\text {adj }}^{2}=.30\right)$.

\section{Functional social support and health}

In order to better understand this disparity, we constructed two stepwise regression models. Criterion variables were the two health measures (objective and perceived health). The predictors were the four dimensions we obtained from the 2-Way Social Support Scale (Shakespeare-Finch \& Obst, 2011), namelly, emotional support given (ESG), emotional support received (ESR), instrumental support given (ISG), and instrumental support received (ISR). As can be seen in table 1, the social support level reported by the participants was quite high in all of the dimensions. Two multiple linear stewise regression analysis were conducted to develop a model for predicting the objective and subjective health indicators from the already mentioned four dimensions of the 2-Way Social Support Scale scores (ESG, ESR, ISG and ISR). Basic descriptive statistics and regression coefficients are shown in table 1 and table 2.

Table 1. Objective Health Indicator (OHI) related to functional Social Support Dimensions (ESG, ESR, ISG and ISR) $(N=168)$

\begin{tabular}{|c|c|c|c|c|c|c|c|}
\hline & \multicolumn{5}{|c|}{ Zero-Order r } & \multirow{2}{*}{ Beta } & \multirow[t]{2}{*}{ First-Order } \\
\hline Variable & ESG & ESR & ISG & $\begin{array}{l}\text { ISR } \\
\end{array}$ & $\mathrm{OIH}$ & & \\
\hline ESG & & $.50^{*}$ & $.53^{*}$ & $.37 *$ & $-.21 *$ & $\begin{array}{l}-.12 \\
\end{array}$ & -.12 \\
\hline ESR & & & $.51 *$ & $.49^{*}$ & $-.28 *$ & $-.26^{*}$ & $-.26^{*}$ \\
\hline ISG & & & & $.53^{*}$ & -.11 & .15 & .01 \\
\hline ISR & & & & & -.02 & .00 & .009 \\
\hline Mean & 79.73 & 89.20 & 81.30 & 84.37 & 2.27 & Intercept $=$ & $4.65^{*}$ \\
\hline$S D$ & 28.36 & 19.43 & 26.28 & 24.87 & 1.95 & $\mathrm{R}_{\text {adj }}^{2}=$ & $.064^{*}$ \\
\hline
\end{tabular}

Table 2. Subjective Health Indicator (SHI) related to functional Social Support Dimensions (ESG, ESR, ISG and ISR) $(N=168)$

\begin{tabular}{lccc}
\hline \multirow{2}{*}{ Variable } & Zero-Order $\mathrm{r}$ & \multirow{2}{*}{ Beta } & \multirow{2}{*}{ First-Order $\mathrm{r}$} \\
\cline { 2 - 3 } & SIH & & \\
\hline ESG & $-.33^{*}$ & $-.22^{*}$ & -.21 \\
\hline ESR & $-.36^{*}$ & $-.26^{*}$ & $-.21^{*}$ \\
\hline ISG & $-.28^{*}$ & -.10 & -.09 \\
\hline ISR & -.11 & .05 & .05 \\
\hline Mean & 2.14 & Intercept $=$ & 3.19 \\
\hline$S D$ & .70 & $\mathrm{R}^{2}{ }_{\text {adj }}=$ & $.13^{*}$ \\
\hline
\end{tabular}

To predict the OHI, on the first step, ESR was entered into the model. None of the remaining predictors were significant. The full model $R^{2}$ was significantly greater than zero $\left[F_{(1,166)}=12.67, p<.001, R^{2}=.064\right]$. As shown in table 1 , every predictor had a significant $(p<.01)$ zero-order correlation with OHI but only the ESR predictor had significant $(p<.01)$ partial effects in the full model.

Predicting the SIH, on the first step ESR was entered into the model 
$\left[F_{(1,166)}=19.55, p<.01\right]$. On the second step ESG was entered into the model. None of the remaining predictors were entered. The full model $R^{2}$ was significantly greater than zero $\left[F_{(2,166)}=14.01, p<.01, R^{2}=.13\right]$. As shown in table 1 , every predictor had a significant $(p<.01)$ zero-order correlation with SHI but only the ESR and ESG predictors had significant $(p<.01)$ partial effects in the full model.

\section{Structural social support and health}

In order to study whether the structural social support may affect differentially health perception, we constructed two stepwise regression models. Criterion variables were the two health measures (objective and perceived health). The predictors were the number of social ties in each of the three circles of Convoy Model of Social Relations (Antonucci, 1986), (circle 1, circle 2 and circle 3).

Table 3. Objective Health Indicator (OHI) related to structural Social Support Dimensions (circle 1, circle 2 and circle 3) $(N=168)$

\begin{tabular}{cccccccc}
\hline & \multicolumn{9}{c}{ Zero-Order $\mathrm{r}$} & \multirow{2}{*}{ Beta } & \multirow{2}{*}{ First-Order $\mathrm{r}$} \\
\cline { 2 - 4 } & Variable & $\mathrm{C} 1$ & $\mathrm{C} 2$ & $\mathrm{C} 3$ & $\mathrm{OIH}$ & & \\
\hline Circle 1 & & & $.27^{*}$ & $.20^{*}$ & -.04 & .00 & .00 \\
\hline Circle 2 & & & .07 & -.03 & -.01 & -.01 \\
\hline Circle 3 & & & & & $-.23^{*}$ & $-.23^{*}$ & $-.23^{*}$ \\
\hline & Mean & 28.55 & 13.42 & 16.29 & 2.27 & Intercept $=$ & $2.95^{*}$ \\
\hline & $S D$ & 13.82 & 9.64 & 11.01 & 1.95 & $\mathrm{R}_{\text {adj }}^{2}$ & $.051^{*}$ \\
\hline
\end{tabular}

Two multiple linear stepwise regression analysis were conducted to develop a model for predicting the objective and subjective health indicators from the frequency of relations in each circle. Basic descriptive statistics and regression coefficients are shown in table 3 and table 4 . To predict the OHI, on the first step, the frequency of relations in circle 3 was entered into the model (see table 3 ). None of the remaining predictors were significant. The full model $R^{2}$ was significantly greater than zero $\left[F_{(1,166)}=9.88, p<.01\right.$, $\left.R^{2}=.051\right]$.

Table 4. Subjective Health Indicator (SHI) related to structural Social Support Dimensions (circle 1, circle 2 and circle 3) $(N=168)$

\begin{tabular}{lccc}
\hline \multirow{2}{*}{ Variable } & Zero-Order $\mathrm{r}$ & \multirow{2}{*}{ Beta } & First-Order $\mathrm{r}$ \\
\cline { 2 - 2 } & $\mathrm{SIH}$ & & \\
\hline Circle 1 & $-.22^{*}$ & $-.17^{*}$ & $-.17^{*}$ \\
\hline Circle 2 & -.14 & -.08 & -.08 \\
\hline Circle 3 & $-.27^{*}$ & $-.24^{*}$ & $-.24^{*}$ \\
\hline Mean & -2.14 & Intercept $=$ & 2.64 \\
\hline$S D$ & .70 & $\mathrm{R}^{2}$ adj $=$ & .09 \\
\hline
\end{tabular}

Predicting the SIH (see table 4), on the first step Circle 3 was entered into the model $\left[F_{(1,166)}=13.44, p<.01\right]$. On the second step Circle 3 was entered into the model. None of 
the remaining predictors were entered. The full model $R^{2}$ was significantly greater than zero $\left[F_{(2,166)}=9.51, p<.01, R^{2}=.09\right]$.

\section{DISCUSSION}

Our first finding has to do with the relationship between objective and subjective health measures in elderly people. We have found divergences between both health measures, shoving only a moderate correlation. Although a number of research supported the conclusion that subjective health ratings are consistent with the objective health status and can serve as a global measure of health status in the general population (Meng, Xie, \& Zhang, 2014), some others authors have found only a moderate level of consistency between both types of measures (Crossley \& Kennedy, 2002; Zajacova \& Dowd, 2011). Thus, present results suggest discrepancies between measures in the line of Zajacova and Dowd (2011) who found that a substantial proportion of individuals $(40 \%)$ changed their ratings across the two interviews over the course of about 1 month. In a similar vein, Crossley and Kennedy (2002) found that the $28 \%$ of participants changed their health rating within the same interview (before and after a detailed battery of health questions).

However divergent health ratings do not mean that older people are unrealistic about their health but that self-rated health seems to be dependent on third variables. In order to explore this possibility, we have proposed various regression models to predict objective (OHI) and subjective (SHI) health indicators from structural and functional social support.

Obtained results regarding functional support showed that while OHI was significantly predicted by emotional support received, SHI was significantly predicted by emotional support received as well as emotional support given. In both models, high emotional support was related with high objective and subjective health. These results are in line with Uchida et al., (2008) who found emotional support is likely to be highly beneficial in cultures that privilege interdependence, such as Spanish culture.

Finally, we explored the extent in which structural support (namely the frequency of relations according Antonucci (1986), may predict health. Our results indicate a significant role of frequency in OHI as well as in SHI. Specifically we have found that whereas the number of relations with persons who play a significant part in our lives, but not on a day-to-day basis (circle 3) plays a relevant role in $\mathrm{OHI}$ and in SHI, the relations with people so close that it would be impossible to imagine life without them (Circle 1) was specifically relevant in order to predict subjective health. These findings support research noting robust links between the absence of social resources and health (Cacioppo, Hawkley, \& Thisted, 2010). 


\section{REFERENCIAS}

Aday, R.H., Aday, K.L., Arnold, J.L., \& Bendix, S.L. (1996). Changing children's perceptions of the elderly: The effects of intergenerational contact. Gerontology \& Geriatrics Education, 16(3), 37-51.

Antonucci, T.C. (1986). Hierarchical mapping technique. Generations: Journal of the American Society on Aging, 10(4), 10-12.

Avlund, K., Lund, R., Holstein, B. E., Due, P., Sakari-Rantala, R., \& Heikkinen, R.L. (2004). The Impact of Structural and Functional Characteristics of Social Relations as Determinants of Functional Decline. The Journals of Gerontology Series B: Psychological Sciences and Social Sciences, 59(1), S44-S51. http://doi.org/10.1093/geronb/59.1.S44

Barerra, M.Jr. (1986). Distinctions between social support concepts, measures, and models. American Journal of Community Psychology, 14, 413-445.

Benjamins, M.R., Hummer, R.A., Eberstein, I.W., \& Nam, C.B. (2004). Self-reported health and adult mortality risk: an analysis of cause-specific mortality. Social Science \& Medicine (1982), 59(6), 1297-1306. http://doi.org/10.1016/j.socscimed.2003.01.001

Bolger, N., \& Amarel, D. (2007). Effects of social support visibility on adjustment to stress: experimental evidence. Journal of Personality and Social Psychology, 92(3), 458-475. http://doi.org/10.1037/0022-3514.92.3.458

Cacioppo, J.T., Hawkley, L.C., \& Thisted, R.A. (2010). Perceived social isolation makes me sad: 5 -year cross-lagged analyses of loneliness and depressive symptomatology in the Chicago Health, Aging, and Social Relations Study. Psychology and Aging, 25(2), 453 463. http://doi.org/10.1037/a0017216

Chamberlain, V.M., Fetterman, E., \& Maher, M. (1994). Innovaction in Elder and child care: An intergeneracional experience. Educational Gerontology, 19, 193-204

Crossley, T.F., \& Kennedy, S. (2002). The reliability of self-assessed health status. Journal of Health Economics, 21(4), 643-658.

Franks, P., Gold, M.R., \& Fiscella, K. (2003). Sociodemographics, self-rated health, and mortality in the US. Social Science and Medicine, 56(12), 2505-2514. http://doi.org/10.1016/S0277-9536(02)00281-2

Gleason, M.E.J., Iida, M., Bolger, N., \& Shrout, P.E. (2003). Daily supportive equity in close relationships. Personality \& Social Psychology Bulletin, 29(8), 1036-1045. http://doi.org/10.1177/0146167203253473

Haber, M.G., Cohen, J.L., Lucas, T., \& Baltes, B.B. (2007). The relationship between self-reported received and perceived social support: a meta-analytic review. American Journal of Community Psychology, 39(1-2), 133-144. http://doi.org/10.1007/s10464-007-9100-9

House, J.S., Landis, K.R., \& Umberson, D. (1988). Social relationships and health. Science (New York, N.Y.), 241(4865), 540-545.

Idler, E.L. (1993). Age differences in self-assessments of health: age changes, cohort differences, or survivorship? Journal of Gerontology, 48(6), S289-300.

Idler, E.L., \& Angel, R.J. (1990). Self-rated health and mortality in the NHANES-I Epidemiologic Follow-up Study. American Journal of Public Health, 80(4), 446-452.

Kafetsios, K., \& Sideridis, G.D. (2006). Attachment, social support and well-being in young and older adults. Journal of Health Psychology, 11(6), 863-875. http://doi.org/10.1177/1359105306069084

Kaplan, G., Barell, V., \& Lusky, A. (1988). Subjective state of health and survival in elderly adults. Journal of Gerontology, 43(4), S114-120. 
Lakey, B., \& Orehek, E. (2011). Relational regulation theory: a new approach to explain the link between perceived social support and mental health. Psychological Review, 118(3), 482495. http://doi.org/10.1037/a0023477

Lehman, D.R., \& Hemphill, K.J. (1990). Recipients' Perceptions of Support Attempts and Attributions for Support Attempts that Fail. Journal of Social and Personal Relationships, 7(4), 563-574. http://doi.org/10.1177/0265407590074012

Lyyra, T.M., \& Heikkinen, R.L. (2006). Perceived Social Support and Mortality in Older People. The Journals of Gerontology Series B: Psychological Sciences and Social Sciences, 61(3), S147-S152.

Martire, L.M., Stephens, M.A., Druley, J.A., \& Wojno, W.C. (2002). Negative reactions to received spousal care: predictors and consequences of miscarried support. Health Psychology: Official Journal of the Division of Health Psychology, American Psychological Association, 21(2), 167-176.

Meng, Q., Xie, Z., \& Zhang, T. (2014). A Single-Item Self-Rated Health Measure Correlates with Objective Health Status in the Elderly: A Survey in Suburban Beijing. Frontiers in Public Health, 2. http://doi.org/10.3389/fpubh.2014.00027

Nurullah, A.S. (2012). Received and Provided Social Support: A Review of Current Evidence and Future Directions (SSRN Scholarly Paper No. ID 2158458). Rochester, NY: Social Science Research Network. Retrieved from http://papers.ssrn.com/abstract=2158458

Sánchez, M., Sáez, J., \& Pinazo, S. (2010). Intergenerational solidarity: Programs and Policy Development [in:] M. SÁNCHEZ (eds.), Intergenerational solidarity. Strngthening economic and social ties, (pp. 129-146). N.Y. : Palgrave Macmillan.

Schulz, R., \& Sherwood, P.R. (2008). Physical and Mental Health Effects of Family Caregiving. The American Journal of Nursing, 108(9 Suppl), 23-27. http://doi.org/10.1097/ 01.NAJ.0000336406.45248.4c

Shakespeare-Finch, J., \& Obst, P.L. (2011). The development of the 2-Way Social Support Scale: a measure of giving and receiving emotional and instrumental support. Journal of Personality Assessment, 93(5), 483-490. http://doi.org/10.1080/00223891.2011.594124

Uchida, Y., Kitayama, S., Mesquita, B., Reyes, J.A.S., \& Morling, B. (2008). Is perceived emotional support beneficial? Well-being and health in independent and interdependent cultures. Personality \& Social Psychology Bulletin, 34(6), 741-754. http://doi.org/10.1177/0146167208315157

Uchino, B.N., Cacioppo, J.T., \& Kiecolt-Glaser, J.K. (1996). The relationship between social support and physiological processes: a review with emphasis on underlying mechanisms and implications for health. Psychological Bulletin, 119(3), 488-531.

Wethington, E., \& Kessler, R.C. (1986). Perceived support, received support, and adjustment to stressful life events. Journal of Health and Social Behavior, 27(1), 78-89.

Wu, S., Wang, R., Zhao, Y., Ma, X., Wu, M., Yan, X., \& He, J. (2013). The relationship between self-rated health and objective health status: a population-based study. BMC Public Health, 13(1), 320. http://doi.org/10.1186/1471-2458-13-320

Zajacova, A., \& Dowd, J.B. (2011). Reliability of Self-rated Health in US Adults. American Journal of Epidemiology, kwr204. http://doi.org/10.1093/aje/kwr204

Received: April 15th, 2015

Modifications Received: July 31st, 2015

Accepted: August 4th, 2015 